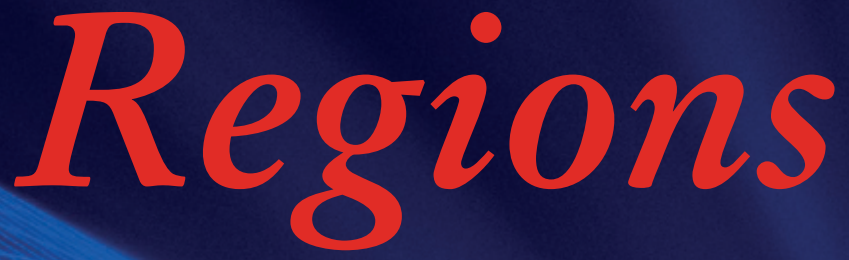

THE VOICE OF THE MEMBERSHIP NO.287, 2012 ISSUE 3
QUARTERLY

MAGAZINE OFTHE Regional Studies

\section{Association}

THE GLOBAL FORUM FOR CITY AND REGIONAL RESEARCH, DEVELOPMENT AND POLICY

- Community assets, social capital and renewable energy

- Regional Development in Turkey 


\title{
INSTITUTIONAL SPACE FOR COMMUNITY BASED RENEWABLE ENERGY PROVISION
}

\author{
Marieke Oteman, Radboud University Nijmegen, the Netherlands
}

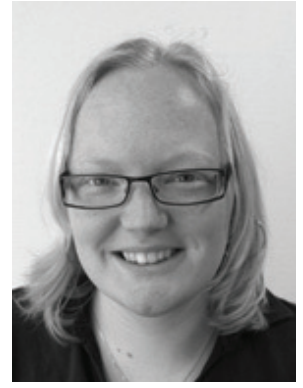

Introduction

Despite the shared ' $20 \%$ of renewable energy by 2020 ' targets for renewable energy of the EU member states, there is a large variation between countries in both output targets for renewable energy production and consumption and policies through which these targets are to be met.

One main difference is the role of communities, as one of the three types of actors involved in the provision of public goods and services, next to the state and market parties (for profit energy companies). Community initiatives and decentralized renewable energy provision are increasingly seen as an alternative to generalized, state-initiated schemes. This is related to the fact that communities have detailed local knowledge, intrinsic motivation, time to invest and the ability to mobilize support and financial resources. However, the degree to which communities are actively involved in renewable energy provision, and the degree to which they are successful, also varies greatly across countries. This research project is interested in exploring the extent to which the interaction between community renewables projects and their institutional environment might explain the variation in success rates. More specifically: we hypothesize the presence and success of community initiatives in renewable energy provision to be a result of the institutional space that is provided - and that agencies are able to create - within the energy policy subsystem.

\section{Variation in presence and success of community initiatives}

Figures on total renewable energy production and consumption are available for EU member states, but estimates of the share of community based renewable energy are less readily available. However, case-study material suggests large variations in the dynamics, developments and success rates of community initiatives. For example, the Netherlands moved from being a front-runner in renewable energy to lagging behind other EU member states in the last decade, with a meagre present share of $4 \%$ of renewable energy consumption. It has a large "not in my backyard' (NIM)BY)- opposition, along with a recent large growth in the number of community initiatives. Another example is Denmark, previously known for its successful community renewable energy schemes, which has seen a decline in community involvement after the liberalization of the energy market. However, its present share of $16 \%$ renewable energy consumption is still one of the highest in Europe. As a last example, Germany has a renewable energy share of about $8 \%$ of its gross inland energy consumption, which is close to the EU average. Its policies stand out for enabling certain community renewable schemes through feed-in legislation, priority grid access and risk reduction. Civil involvement has been moderately high, but largely consists of individual farmers rather than organized communities. We analyze these differences through the concept of institutional space.

\section{Institutional space}

We use institutional space as an analytical concept, and define it as the degree of freedom of one actor in relation to other actors in the energy subsystem, to decide autonomously about the design of a policy process or a project (in terms of procedures and planning) and its contents (in terms of goals and means). This does not only include the absence of constraints, such as prohibiting rules and regulation, but also the presence of possibly enabling conditions such as subsidy schemes. Institutional space is shaped through rules and resource distribution, but also through the dominant discourse on renewable energy and community involvement. To map the institutional space of communities, we chose an approach that has an operational, analytical framework and that incorporates the duality of structure and agency. It therefore had to take into account both discourse and resources, and the interaction between communities and their institutional environment. We chose to use the policy arrangements approach (PAA), which analyzes the institutional arrangement of a policy or theme in terms of actors, resources, rules and discourse (Leroy and Arts, 2006, p. 13). The resulting sketch of the subsystem demonstrates the institutional space of community initiatives, and could explain NIMBY movements as well as variation in the degree of active involvement of communities across countries.

Institutional space is not limited to a single spatial level. Both at the national level and the regional and local levels, institutional space is shaped and altered, especially for communities, which typically act at the local level under conditions that are determined locally, regionally and nationally. We therefore argue for a multi-level analysis that includes these vertical dynamics.

\section{Institutional arrangements}

The institutional space is not a 'given', nor is it random. We consider the structure of the system and the agency of community actors to be interdependent and mutually influencing. At the same time however, we believe that institutional space is influenced by the institutional arrangement of a country as a whole, that is: its interplay between state, market, and civil society.

Traditionally, four types of ideal typical institutional arrangements have been distinguished, each with its own dominant steering mechanisms (Streeck and Schmitter, 1985). A market oriented system will have market players as its most influential actors, and act upon a rationale of dispersed competition. A state dominated or bureaucratic system will have hierarchical control as a guiding principle, and a civil society or community oriented system will be based on spontaneous solidarity. Fourth, an associational order will be governed through an institutionalized associational structure (ibid.). The institutional space for community based renewable energy 


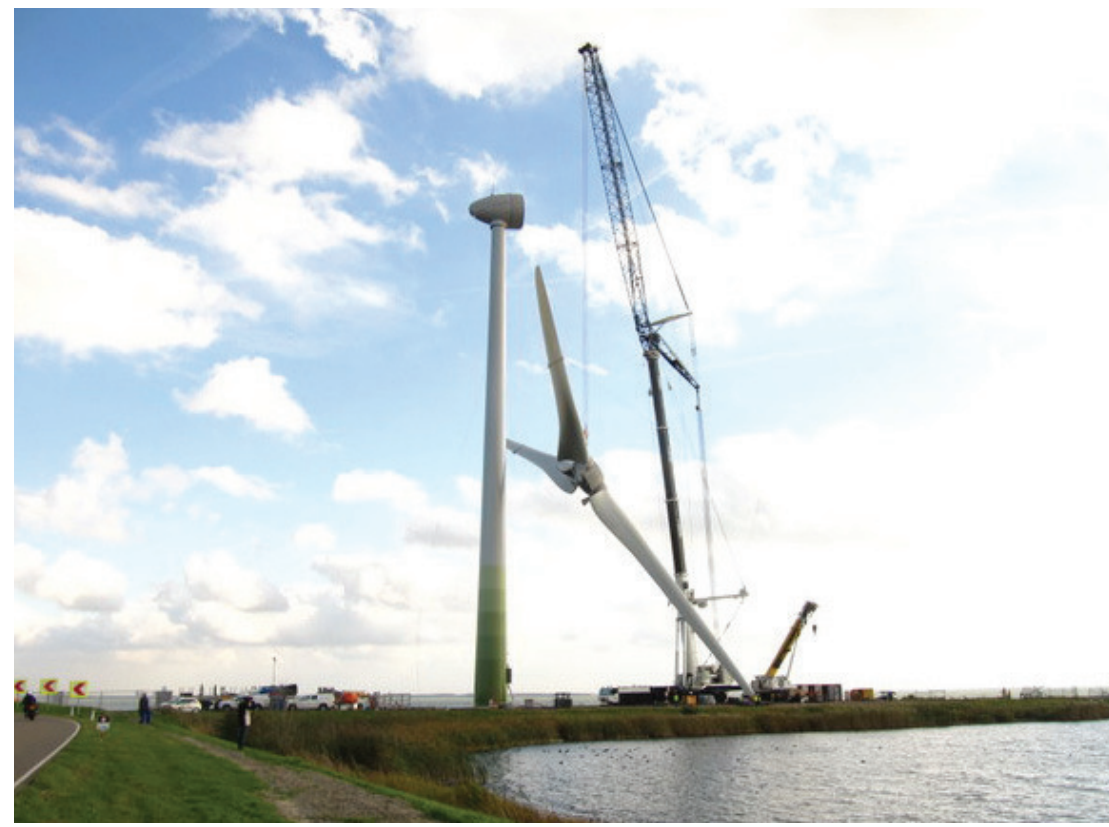

Building a cooperative windmill in Waterland, the Netherlands.

is likely to vary between these types of institutional arrangements.

A system dominated by state hierarchy can both enable and constrain communities. State steering increases the chances of success for certain types of community initiatives, namely those that are institutionally supported through funding or permission schemes. At the same time, hierarchical control and state primacy decreases the discretionary space of community initiatives and subordinates their role to the role of the state. The discourse will probably not be as enabling for community initiatives as with the community-oriented system. In this second institutional arrangement, communities have a stronger 'natural' position and the other actors are likely to provide an enabling environment for community initiatives in renewable energy provision. The latter however is a condition for occurrence and success of community initiatives: because the resources of communities will be limited, government and market parties need to offer both space and support. The market-oriented system will generally benefit large-scale market players and therefore leave little room for projects that are non-profit and/or small-scale. Moreover, this institutional arrangement generally lacks uniformity in rules and policies at the decentralized level, which makes it more incomprehensible and inaccessible for communities. The . with market tasks such as profitability and governmental responsibilities such as functions to local groups and associations and a new, diminished role of the state (Baccaro, 2005). Although we do not (yet) recognize this ideal type in practice, the transition towards a model that is more corporatist would increase the institutional space for community initiatives.

Our current research investigates the hypothesis that institutional space and the institutional arrangement of a country influence the occurrence and success of community initiatives in renewable energy, through a comparison between the Netherlands as a market-dominated system; Denmark as a communitygoverned system; and Germany as a state-oriented system. Through mapping the institutional space and dynamics (including possible transitions towards a more corporatist associational order) as well as comparing success rates, we hope to gather enough empirical data to support or reject our institutional space thesis, which so far is largely a theoretical argument.

\section{Conclusion}

Despite common goals, directives and renewable energy targets, the share of production and consumption of renewable energy varies greatly across EU member states, as does the degree of involvement of communities. We seek an explanation in this variety in the institutional space for community initiatives in the energy policy subsystem, which we treat as a discursiveinstitutionalist concept. Institutional space is dynamic and can be influenced by community agency, but also depends largely on the institutional arrangement of a country in terms of its resemblance to one of the four ideal typical arrangements and its dominant steering mechanism. An analysis of the success of community initiatives in a country should therefore include the notion of institutional space and the dominant institutional arrangement. Similarly, policies to stimulate community initiative should focus on enlarging the institutional space and structural characteristics that are enabling for communities, including emphasis on the possible role and capacities of communities, rather than simply providing financial and/or regulatory stimuli. safety. This would include a devolution of

\section{References}

Baccaro, L. (2005) "Civil society meets the state: towards associational democracy?", Socio-Economic Review, Vol. 4, pp. 185-208.

Leroy, P. and Arts, B. (2006) "Institutional Dynamics" in B. Arts and P. Leroy (eds) Institutional Dynamics in Environmental Governance, Springer, Dordrecht.

Streeck, W. and Schmitter, P. (1985) "Community, market, state, and associations? The prospective contribution of interest governance to social order", European Sociological Review, Vol, 1 No. 2, pp. 119-38.

Marieke Oteman is a $\mathrm{PhD}$ student at the Environmental Policy research group of the Institute of Management Research, Radboud University research interests include renewable energy policy, community initiatives and institutional arrangements analysis. m.oteman@fm.ru.nl Nijmegen, the Netherlands. Her 


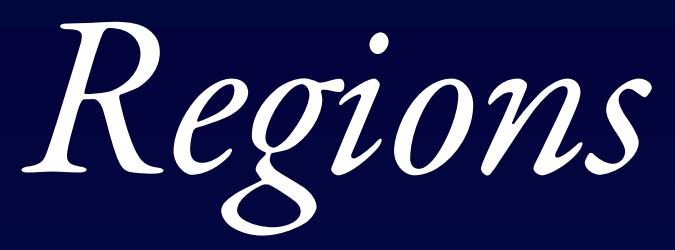

TheV VICE OF THE MEMBERSHIP

'Global warming' is a classic case of a global problem which requires 'local' solutions. The papers in the Regional Survey of this issue, attempt to explore the possibilities of such solutions. Our Guest Editors (Geoff Whittam and George Callaghan) draw together five summary papers that were delivered at the RSA Research Network, Acquiring Community Assets, the Role of Social Capital and Establishment of Alternative Energy Resources, hosted at the Gigha Hotel on the community-owned isle of Gigha off the coast of Argyll in Scotland, in March 2012. The context for the workshop and indeed the Research Network can be found in the growing emphasis being placed on the development of alternative energy systems by policy-makers as 'global warming' continues to move to the top of political agendas. What is increasingly apparent is that whilst the majority of people support alternative energy systems, the introduction of such schemes is not without opposition. It would appear that this opposition is somewhat diminished when the 'community' has a stake in the alternative energy resource. The common theme amongst the papers is to highlight differing approaches to community involvement with alternative energy schemes. There are contributions from researchers and practitioners from around Europe and North America.

Our 'In Depth' article by Arda Akbulut, RSA Ambassador in Turkey, looks at the background to regional development in Turkey and the establishment of RDA's. This issue also contains articles that provoke debate on controversial subjects, including the regional benefits (and costs) associated with 'mega-transport projects' such as the high-speed trains investment announced in the UK; and the potential economic impacts of gambling casinos and their possible negative social consequences.

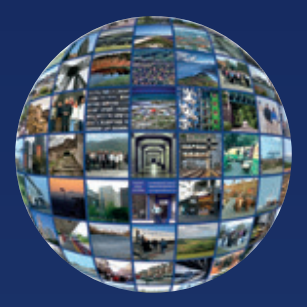

Regional Studies Association, PO Box 2058, Seaford, East Sussex BN25 4QU, UK Tel: 0044 (0)1323 899 698, Fax: 0044 (0)1323 899798 info@regionalstudies.org, www.regionalstudies.org

Registered Charity No: 1084165

Registered Company, Limited By Guarantee In England No: 4116288 